\title{
Balloon-Assisted Creation and Maturation of an Arteriovenous Fistula in a Patient with Small-Caliber Vasculature
}

\author{
Atsushi Kotoda ${ }^{a, b}$ Tetsu Akimoto $^{a}$ Taro Sugase $^{a, b}$ \\ Naoshi Miyamoto ${ }^{b}$ Eiji Kusano $^{a}$ \\ ${ }^{a}$ Division of Nephrology, Department of Internal Medicine, Jichi Medical \\ University, and ${ }^{b}$ Kotoda Jin Clinic, Shimotsuke, Japan
}

\section{Key Words}

Balloon angioplasty $\cdot$ Maturation $\cdot$ Radial-cephalic arteriovenous fistula $\cdot$ Vascular access failure $\cdot$ Hemodialysis

\section{Abstract}

The major problem associated with the creation of an arteriovenous fistula (AVF), which is the optimal form of vascular access for hemodialysis, is the fact that fistulas do not necessarily mature into a usable vascular access, requiring subsequent revision and construction of another access. The caliber of the vessels used for fistula creation is a pivotal factor predicting the presumable maturation of the constructed fistula, and veins less than $2.5 \mathrm{~mm}$ in diameter have poor outcomes. This report describes the balloon-assisted creation and maturation of an autogenous radial-cephalic AVF in a patient with a small-caliber vein and a radial artery measuring approximately 2 and $1.5 \mathrm{~mm}$ in diameter, respectively. The clinical impact of percutaneous radiological intervention for expediting the maturation of an autogenous AVF with small-caliber vessels is also discussed.

\section{Introduction}

An autogenous arteriovenous fistula (AVF) is the optimal form of vascular access for hemodialysis (HD) due to the longer duration of patency, fewer infections, and lower mortality $[1,2]$. The presence of occlusive neointimal hyperplasia at the anastomosis and/or the outflow veins, which may be accelerated by chronic kidney disease [2], has been considered to be the leading cause of AVF failure, while the major problem 
associated with the creation of an AVF is the fact that fistulas do not necessarily mature into a usable vascular access, requiring subsequent revision and construction of another access [3]. The caliber of the vessels used for fistula creation is a pivotal factor predicting the presumable maturation of the constructed fistula, and veins less than 2.5 $\mathrm{mm}$ in diameter have poor outcomes [3]. This report describes the balloon-assisted creation and maturation of an autogenous radial-cephalic arteriovenous fistula (RCF) in a patient with small-caliber veins and a radial artery of approximately 2 and $1.5 \mathrm{~mm}$ in diameter, respectively.

\section{Case Report}

A 78-year-old female with end-stage renal failure caused by diabetic nephropathy had been undergoing HD treatment for 9 years. Her medical history included arteriosclerosis obliterans, an old myocardial infarction, and complete atrioventricular block, which was managed by the implantation of a definitive pacemaker via the right subclavian vein. She first began undergoing HD through a left upper arm brachial-cephalic AVF, since a forearm RCF created before initiating HD did not mature despite repeated surgical revisions. The fistula failed 2 years later because of a thrombotic occlusion presumably induced by frequent postdialytic hypotension resulting from excessive interdialytic weight gain. The patient underwent numerous vascular access interventions, including percutaneous transluminal angioplasty and stenting for thrombotic or stenotic lesions, not only in accessory veins, but also in the central venous system. Therefore, the fistula was salvaged, but with varying degrees of patency. The peripheral venous access in the left upper extremity seemed to be exhausted 5 years after the initial intervention, and the right brachial artery was superficially repositioned [4]. The peripheral venous system in the right upper extremity also did not seem to be feasible to use as the return route, so the patient was dialyzed with a silicone tunneled cuffed catheter inserted through the right femoral vein. However, thrombotic catheter occlusion developed 5 months after the insertion, and the catheter could only be used for the return route. The repositioned right brachial artery was used as a vascular access. Finally, a balloon-assisted procedure was used to try to create and expedite the maturation of the autogenous right forearm RCF. Small-caliber veins of approximately $2 \mathrm{~mm}$ and a radial artery of $1.5 \mathrm{~mm}$ in diameter were confirmed by preoperative digital subtraction angiography (DSA).

The cephalic vein and radial artery were exposed through a transverse incision at the wrist using magnification glasses (3.0x). The vein was then freed by wide dissection, and the collateral branch was ligated, followed by a longitudinal venotomy of the posterior wall. The anterior wall of the radial artery was exposed without any dissection of its trunk, and a 5-mm longitudinal arteriotomy was made. A side-to-end, artery-to-vein anastomosis was created with four running 7-0 polypropylene sutures. Palpation just after the creation of the anastomosis failed to confirm the patency of the fistula, and subsequent DSA revealed the stenosis of the juxta-anastomotic vein. A short 4-Fr sheath was placed through the distal radial arterial puncture site. Next, the stenotic lesion of the juxtaanastomotic radiocephalic vein was crossed with a 0.018-inch hydrophilic guide wire, and a 3-mm (40 mm long) balloon catheter (Sterling Balloon Dilatation Catheter, Boston Scientific, Natick, Mass., USA) was inflated to $6 \mathrm{~atm}$ for at least $1 \mathrm{~min}$, with one overlapping angioplasty under direct visualization (fig. 1). Patency was confirmed by palpation and final fistulography. The patient underwent subsequent balloon angioplasty on days 20 and 60 to aid in the maturation of the radial artery and the usable portion of the RCF. Balloon angioplasty was performed under radiological guidance on day 20 , with a retrograde radial arterial approach using a 0.018-inch platform combined with a 4-mm balloon catheter for the radial artery (inflated to $4 \mathrm{~atm}$ for $10 \mathrm{~s}$ ), anastomotic region (inflated to $6 \mathrm{~atm}$ for 20 $\mathrm{s}$ ), and the juxta-anastomotic region (inflated to $8 \mathrm{~atm}$ for $20 \mathrm{~s}$; fig. 2). Angioplasty was performed on day 60 , using a 5 -mm balloon catheter from the anastomotic to the juxta-anastomotic lesion. Followup fistulography was performed 3 months later, when the RCF became functional and the tunneled cuffed catheter was removed, revealing the matured radial artery and cephalic vein (fig. 3 ). The right RCF has been functional for more than 6 months since the final fistulography. 


\section{Discussion}

A wrist AVF including an RCF has been the first choice of vascular access for chronic $\mathrm{HD}$, since it is simple to create and preserves more proximal vessels for future access placement with fewer complications than other fistula types [5]. However, a high level of surgical experience appears to affect the primary success and patency rate of an RCF, thus suggesting that the construction of such access is technically demanding [6]. On the other hand, the availability of a distal cephalic vein and radial artery will become even more limited for arteriovenous fistula construction with the increasing average age of the end-stage renal failure population [7]. The survival rate of a successfully created forearm autogenous RCF is excellent, and the 2-year complication-free survival of such a fistula is approximately 75\% [8], while another study by Miller et al. [9] demonstrated that the overall success rate of forearm RCF is rather poor. Therefore, it is not unusual that the left forearm RCF created in the current patient before initiating HD did not mature despite repeated surgical revisions.

Several studies have evaluated factors that might predict fistula maturation, and preoperative vascular mapping has been shown to improve the rate of fistula placement and overall surgical success rate [3]. In addition, the criteria for the placement of an autogenous fistula have included a minimum artery diameter of $2 \mathrm{~mm}$, a minimum vein diameter of $2.5 \mathrm{~mm}$, and a lack of stenosis or thrombosis in the draining vein or central veins $[3,8]$. The experience in the current patient with a suboptimal artery measuring approximately $1.5 \mathrm{~mm}$ in size and veins measuring 2.0 $\mathrm{mm}$ in diameter suggests the clinical benefit of balloon-assisted creation and maturation of an autogenous right forearm RCF. Although one may argue that perioperative radiological intervention could be dangerous due to the risk of disruption of the anastomosis [10], intraoperative interventions are not exceptional and are occasionally indicated in clinical settings [11]. The most common reason is limited percutaneous vascular access, such as with lesions proximal or distal to a stenosed or occluded portion that is simultaneously treated by vasculotomy [11]. The directly visualized intraoperative procedure may avoid the development of several adverse events, such as vascular perforation or rupture. The balloon-assisted intraoperative intervention was mandatorily applied to the current patient.

Variability in the techniques used for creating AVFs has made it difficult to objectively analyze the results and develop best practice recommendations, despite a large amount of literature on the subject and continued technological advances [12]. In addition, there are no clear protocols to address accessible vessel maturation with regard to an AVF. The application of intraoperative balloon angioplasty and the subsequent interventional approach has allowed the maturation of an autogenous AVF with suboptimal vessels that otherwise could not have been used $[13,14]$. The mechanisms of successful balloon angioplasty with vascular access stenoses involves vessel stretching and dissection, which are similar to the mechanisms that have been validated with morphological evaluation of arterial balloon angioplasty $[15,16]$. On the other hand, the vascular access portions dilated by repeated balloon angioplasty are thought to heal mostly by fibrosis, and eventually to become large-diameter fibrous segments $[15,16]$. Further studies and more extensive clinical experience are required to better determine the optimal interval and appropriate duration of balloon 
angioplasty not only for post-dilation healing, but also for expediting the maturation of an autogenous AVF with small-caliber vasculature.

\section{Disclosure Statement}

The authors declare no conflicts of interest.
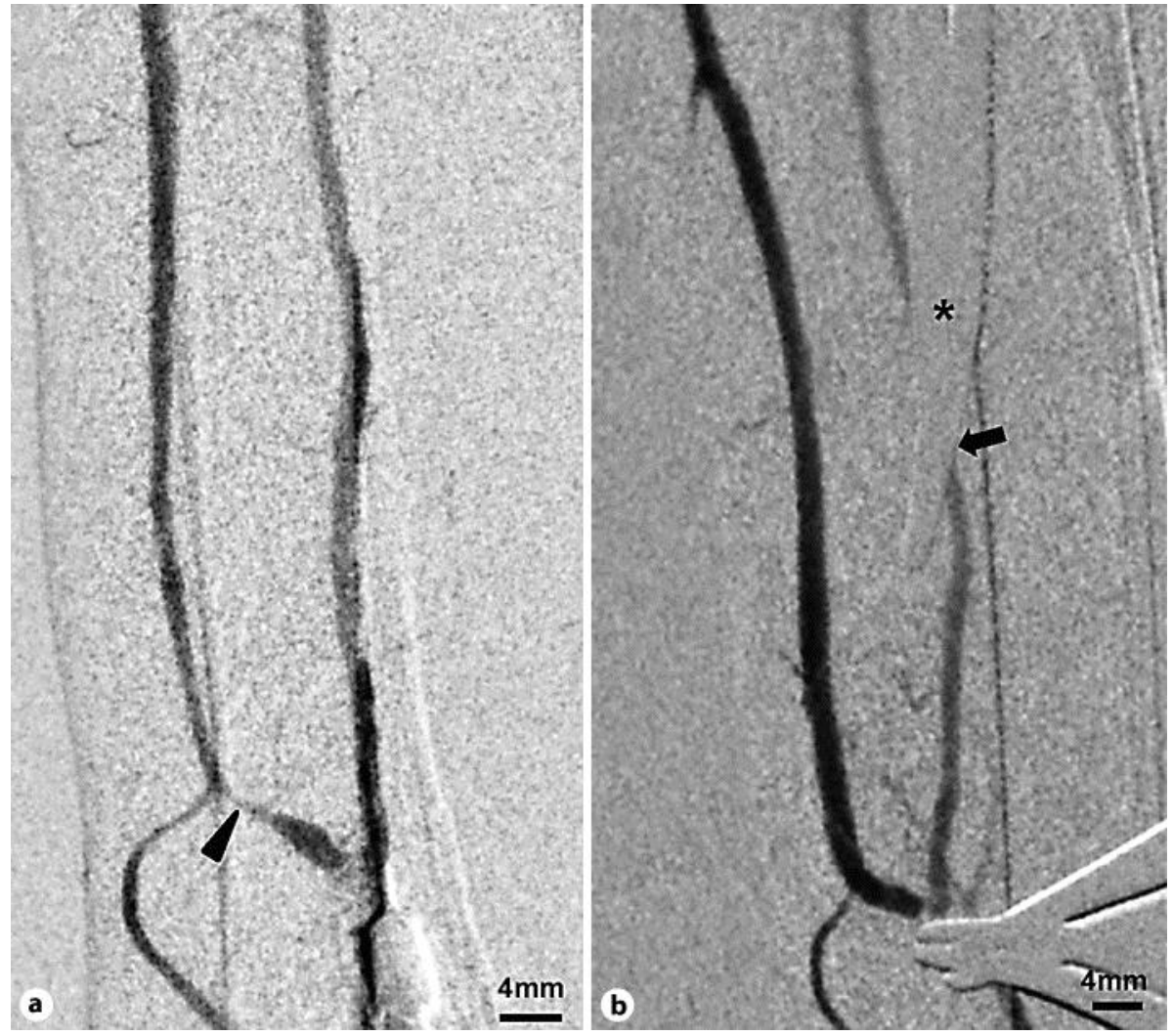

Fig. 1. A fistulogram obtained just after the creation of the RCF revealed diffuse stenosis of the juxtaanastomotic cephalic vein (arrowhead) (a). Balloon angioplasty was applied to the stenotic lesion, and patency was confirmed by final fistulography. Note that there is an artifact defect induced by a Pean forceps $\left({ }^{*}\right)$ in the contrast image of the radial artery (arrow) (b). A scale bar is shown in each panel. 


\section{Case Reports in Nephrology and

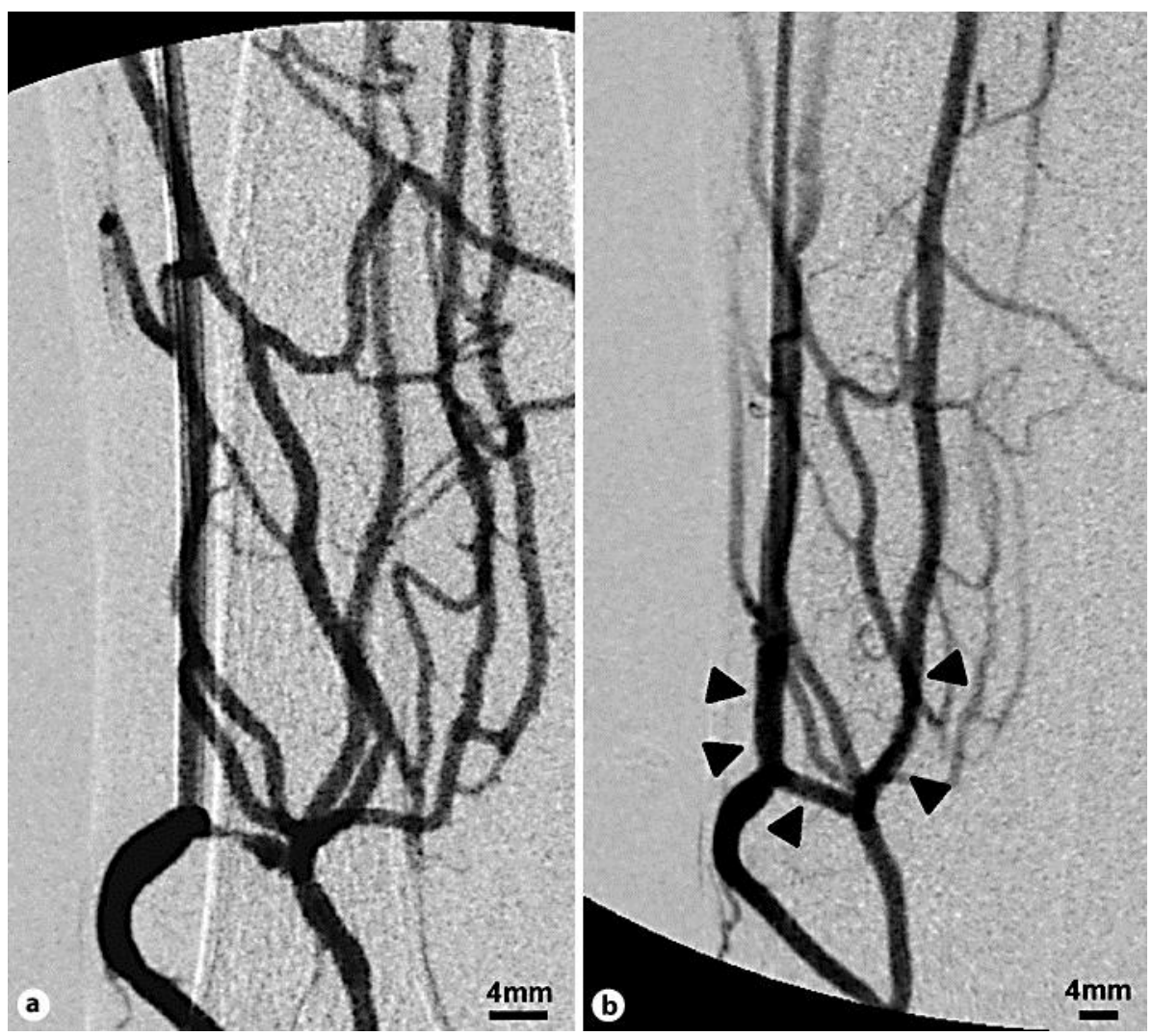

Fig. 2. A fistulogram on day 20 (a). The hydrophilic straight guide-wire was passed through the cephalic vein, and balloon angioplasty was applied to the radial artery, anastomotic region, and juxta-anastomotic region. The final fistulogram (b) shows the widely dilated vasculature (arrowheads). A scale bar is shown in each panel. 


\begin{tabular}{c|l|l|l}
$\begin{array}{r}\text { Case Reports in } \\
\text { Nephrology and } \\
\text { Urology }\end{array}$ & $\begin{array}{l}\text { Case Rep Nephrol Urol 2012;2:65-71 } \\
\text { DOl: 10.1159/000339501 }\end{array}$ & $\begin{array}{l}\text { Published online: } \\
\text { June 5, 2012 }\end{array}$ & $\begin{array}{l}\text { @ 2012 S. Karger AG, Basel } \\
\text { ISSN 1664-5510 } \\
\text { www.karger.com/cru }\end{array}$ \\
\hline
\end{tabular}

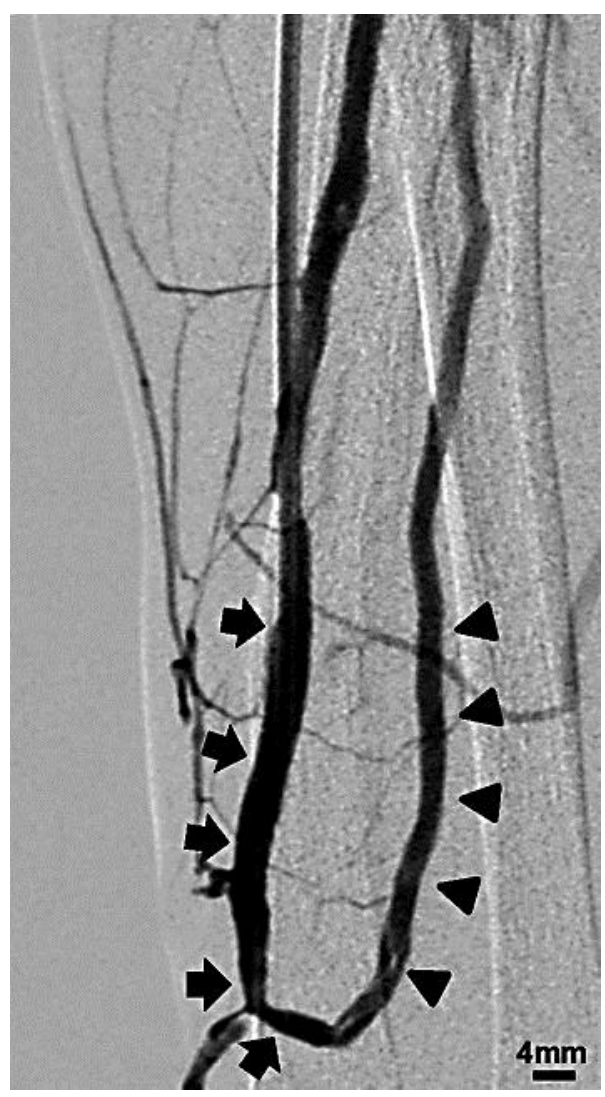

Fig. 3. Follow-up fistulography performed at three months after the third angioplasty (day 60), when the RCF had become functional and the tunneled cuffed catheter was removed, thus revealing the matured radial artery (arrowheads) and cephalic vein (arrows). The scale is indicated.

\section{References}

1 Clark TW, Cohen RA, Kwak A, Markmann JF, Stavropoulos SW, Patel AA, Soulen MC, Mondschein JI, Kobrin S, Shlansky-Goldberg RD, Trerotola SO: Salvage of nonmaturing native fistulas by using angioplasty. Radiology 2007;242:286-292.

-2 Kokubo T, Ishikawa N, Uchida H, Chasnoff SE, Xie X, Mathew S, Hruska KA, Choi ET: CKD accelerates development of neointimal hyperplasia in arteriovenous fistulas. J Am Soc Nephrol 2009;20:1236-1245.

-3 Allon M, Robbin ML: Increasing arteriovenous fistulas in hemodialysis patients: problems and solutions. Kidney Int 2002;62:1109-1124.

-4 Ohira S, Naito H, Amano I, Azuma N, Ikeda K, Kukita K, Goto Y, Sakai S, Shinzato T, Sugimoto T, Takemoto Y, Haraguchi H, Hino I, Hiranaka T, Mizuguchi J, Miyata A, Murotani N: 2005 Japanese Society for Dialysis Therapy guidelines for vascular access construction for chronic hemodialysis. Ther Apher Dial 2006;10:449-462.

5 National Kidney Foundation: K/DOQI Clinical Practice Guideline for Vascular Access, 2000. Am J Kidney Dis 2000;37(suppl 1):S137-S181.

6 Fassiadis N, Morsy M, Siva M, Marsh JE, Makanjuola AD, Chemla ES: Does the surgeon's experience impact on radiocephalic fistula patency rates? Semin Dial 2007;20:455-457.

7 Hingorani A, Ascher E, Kallakuri S, Greenberg S, Khanimov Y: Impact of reintervention for failing upperextremity arteriovenous autogenous access for hemodialysis. J Vasc Surg 2001;34:1004-1009.

-8 Brimble KS, Rabbat ChG, Treleaven DJ, Ingram AJ: Utility of ultrasonographic venous assessment prior to forearm arteriovenous fistula creation. Clin Nephrol 2002;58:122-127. 
9 Miller PE, Tolwani A, Luscy CP, Deierhoi MH, Bailey R, Redden DT, Allon M: Predictors of adequacy of arteriovenous fistulas in hemodialysis patients. Kidney Int 1999;56:275-280.

10 Aruny JE, Lewis CA, Cardella JF, Cole PE, Davis A, Drooz AT, Grassi CJ, Gray RJ, Husted JW, Jones MT, McCowan TC, Meranze SG, Van Moore A, Neithamer CD, Oglevie SB, Omary RA, Patel NH, Rholl KS, Roberts AC, Sacks D, Sanchez O, Silverstein MI, Singh H, Swan TL, Towbin RB, Trerotola SO, Bakal CW; Society of Interventional Radiology Standards of Practice Committee: Quality improvement guidelines for percutaneous management of the thrombosed or dysfunctional dialysis access. J Vasc Interv Radiol 2003;14(suppl 2):S247-S253.

11 Guidelines for percutaneous transluminal angioplasty: Standards of Practice Committee of the Society of Cardiovascular and Interventional Radiology. Radiology 1990;177:619-626.

12 Forauer AR, Hoffer EK, Homa K: Dialysis access venous stenoses: treatment with balloon angioplasty - 1versus 3-min inflation times. Radiology 2008;249:375-381.

13 De Marco Garcia LP, Davila-Santini LR, Feng Q, Calderin J, Krishnasastry KV, Panetta TF: Primary balloon angioplasty plus balloon angioplasty maturation to upgrade small-caliber veins $(<3 \mathrm{~mm})$ for arteriovenous fistulas. J Vasc Surg 2010;52:139-144.

14 Chawla A, DiRaimo R, Panetta TF: Balloon angioplasty to facilitate autogenous arteriovenous access maturation: a new paradigm for upgrading small-caliber veins, improved function, and surveillance. Semin Vasc Surg 2011;24:82-88.

15 Kotoda A, Akimoto T, Kato M, Kanazawa H, Nakata M, Sugase T, Ogura M, Ito C, Sugimoto H, Muto S, Kusano E: Central venous stenosis among hemodialysis patients is often not associated with previo us central catheters. ASAIO J 2011;57:439-443.

16 Davidson CJ, Newman GE, Sheikh KH, Kisslo K, Stack RS, Schwab SJ: Mechanisms of angioplasty in hemodialysis fistula stenoses evaluated by intravascular untrasound. Kidney Int 1991;40:91-95. 